\section{Regards sur l'économie allemande}

Bulletin économique du CIRAC

$115 \mid 2014$

Varia

\title{
Emploi : les jeunes Allemands sont bien insérés
}

\section{Solène Hazouard}

\section{OpenEdition}

Journals

Édition électronique

URL : http://journals.openedition.org/rea/4766

DOI : 10.4000/rea.4766

ISSN : 1965-0787

Éditeur

CIRAC

Édition imprimée

Date de publication : 1 décembre 2014

Pagination : 35

ISSN : 1156-8992

\section{Référence électronique}

Solène Hazouard, «Emploi : les jeunes Allemands sont bien insérés », Regards sur l'économie allemande

[En ligne], 115 | décembre 2014, mis en ligne le 01 décembre 2016, consulté le 15 septembre 2020 URL : http://journals.openedition.org/rea/4766

Ce document a été généré automatiquement le 15 septembre 2020.

(c) CIRAC 


\title{
Emploi : les jeunes Allemands sont bien insérés
}

\author{
Solène Hazouard
}

La mise en œuvre de la « garantie pour la jeunesse » au sein de l'UE...

1 Début décembre, les responsables européens des services publics de l'emploi se sont réunis à Rome afin de discuter des nouvelles avancées à effectuer dans le cadre de la "garantie pour la jeunesse » adoptée en avril 2013 par les Etats de l'UE. Il s'agit de proposer à tous les moins de 25 ans (inscrits au chômage ou non) un emploi, un apprentissage, un stage ou une formation continue dans les quatre mois suivant la fin de leur scolarité ou la perte de leur emploi. Cet enjeu est crucial dans le contexte actuel de la crise dans la zone Euro, d'autant que selon les estimations du rapport NEETsYoung people not in employment, education or training: Characteristics, costs and policy responses in Europe publié en 2012 par Eurofound, les jeunes sans emploi et ne poursuivant ni études, ni formation (NEET) coûtent non moins de 153 milliards $€$ par an à l'UE en allocations chômage ainsi qu'en pertes de revenus et d'impôts. Une somme importante comparée au coût total de la mise en place du dispositif dans la zone Euro qui, selon le rapport de l'Organisation internationale du travail (OIT), EuroZone job crisis: trends and policy responses, paru en 2012, s'établirait à 21 milliards $€$ par an.

... ne concerne pas prioritairement l'Allemagne...

2 Si l'Agence fédérale pour l'emploi, responsable de la politique active pour l'emploi à destination des jeunes (qualification, intégration), suit de près ce programme européen, l'Allemagne n'en constitue pas la principale cible. En effet, dans son rapport 2013/14, le Conseil des Sages indiquait qu'en 2012, le pays enregistrait en comparaison européenne le plus faible taux de chômage des $15-24$ ans $(8,1 \%)$ et l'un des plus faibles taux de NEET (7,7\%). Plus marquant encore, l'Allemagne était le seul pays européen à avoir vu reculer ces deux taux depuis le début de la crise en 2007.

... qui bénéficie notamment d'un système de formation duale particulièrement efficace

3 Ce succès est notamment à attribuer à la formation initiale par l'apprentissage dans le cadre du système de formation duale (voir l'article de René Lasserre dans REA 
113/2014). Ce dernier offre la possibilité à de nombreux jeunes de réussir leur insertion professionnelle. Selon une enquête de l'Institut de recherche sur le marché du travail et les professions (Institut für Arbeitsmarkt und Berufsforschung, IAB) de l'Agence fédérale pour l'emploi, menée auprès d'un échantillon représentatif de quelque 16000 entreprises, près des deux tiers des apprentis diplômés en 2013 ont été embauchés par leur entreprise formatrice. Le taux de recrutement atteint ainsi son plus haut niveau depuis la première enquête réalisée en 1996.

\section{Des initiatives sont élaborées afin d'aider les jeunes en difficulté}

Qui plus est, des initiatives fleurissent outre-Rhin pour inscrire les jeunes en difficulté dans une dynamique d'insertion professionnelle. Depuis 2006, par exemple, la Fédération allemande de football (DFB) mise sur l'intégration par le sport, en partenariat avec l'Agence fédérale pour l'emploi. Actuellement et jusqu'à fin 2016, leur coopération se poursuit au sein de la maison de redressement de Berlin afin de préparer les délinquants à leur sortie et de faciliter la transition vers la formation ou l'emploi. A travers un entraînement sportif hebdomadaire, les détenus de 16 à 24 ans développent à la fois fair-play, esprit d'équipe et compétences sociales. Ils se voient proposer des formations pour devenir arbitre ou entraîneur et peuvent participer à des programmes de lutte contre la violence ou à des entretiens d'orientation comprenant des ateliers de recherche d'emploi.

\section{Le capital humain, facteur de compétitivité}

5 Les compétences sociales ainsi acquises se révéleront d'une grande utilité pour intégrer par la suite le système de formation duale qui contribue, via la transmission d'un niveau élevé de qualification, à la valorisation du facteur humain dans l'entreprise et, plus globalement, à la compétitivité de l'économie allemande.

\section{INDEX}

Mots-clés : apprentissage, formation, insertion, jeunes, marché du travail, UE 